\section{Dominant Positive and Negative Selection Using Luciferase, Green Fluorescent Protein and $\beta$-Galactosidase Reporter Gene Fusions}

BioTechniques 28:210-214 (February 2000)

The introduction of exogenous DNA sequences into cultured cells is a cornerstone in the study of mammalian gene expression. For most cell types, the efficiency of stable gene transfer is usually quite low, which mandates the use of selectable markers to isolate a population of transfected cells with the desired phenotype. In simple gene expression experiments, only one type of selectable marker is required. Positive selectable markers such as the bacterial $n e o$ and $h p h$ genes facilitate the direct selection for cells that are resistant to the cytocidal effects of the antibiotics, G418 and hygromycin B, respectively $(1,12)$. Conversely, negative selectable markers facilitate the elimination of the cells in which they are expressed.

The most popular negative selectable marker is the herpes simplex virus thymidine kinase gene, $t k$, which sensitizes cells to the toxic effects of the nucleoside analogue gancyclovir $(11,15)$. In more complex gene transfer experiments such as in the use of gene, promoter or enhancer traps, it becomes necessary to include multiple marker genes. For example, fusions between the bacterial lac $\mathrm{Z}$ reporter gene and the selectable neo marker (2), the $h p h$ and tk selectable markers (7) or the neo and $t k$ selectable markers have been developed for use in enhancer or gene trapping experiments. Here, we describe the further development of gene fusions between the $t k$ and neo selectable markers and the bacterial lacZ, jellyfish $g f p$ and firefly $l u c$ reporter genes.

The gene fusions were constructed using cDNAs derived from the previously described pPNT (14), pßgeo (2), pGL3-Control (Promega, Madison, WI, USA), and pEGFP-C1 (Clontech Laboratories, Palo Alto, CA, USA) vector constructs, which encode the HSV $t k$ and bacterial neo genes, a lacZ-neo fu- sion gene, the enhanced $l u c$ and $g f p$ reporter genes, respectively. A tkneo gene fusion was generated using PCR amplification in conjunction with vector-specific primers to eliminate the endogenous stop codon in the $t k$ gene of pPNT through the incorporation of a BamHI site. The amplified product was cloned as an EcoRI-BamHI fragment into the corresponding EcoRI-BamHI sites of $\mathrm{p} \beta \mathrm{geo}$, which effectively replaces the lacZ-portion of the lacZ-neo gene fusion. The tkneo fusion gene was then subcloned as a HindIII-NotI fragment into the pEFG3 expression vector, and this construct was designated pEF-tkneo (Figure 1). We incorporated the $g f p$ cDNA by subcloning the corresponding reading frame as a blunt-ended NheI$B g l$ II fragment from pEGFP-C1 into the blunt-ended BamHI site to generate pEF-tkgfneo.

The tklucneo gene fusion was generated using PCR amplification in conjunction with vector-specific primers to introduce $\mathrm{PacI}$ restriction endonuclease sites into the $5^{\prime}$-UTR and to eliminate the endogenous stop codon in the luc gene of pGL3-Control, which was then subcloned into the BamHI site of pEFtkneo to generate $\mathrm{pEF}-\mathrm{tk} \beta$ geo (Figure 1). The lac Z gene was incorporated into the tkneo gene fusion by subcloning the corresponding reading frame as a Bam $\mathrm{HI}$ fragment from $\mathrm{p} \beta$ geo into the BamHI site of pEF-tkneo to generate pEF-tk $\beta$ geo (Figure 1). The $g f p$ cDNA was incorporated into the BamHI site of this construct to generate pEFT $\beta$ GN (Figure 1). As positive control plasmids for our experiments, we subcloned the individual $l u c, g f p$ and $l a c Z$ genes into the $\mathrm{pEF} 1$ vector (Invitrogen, Carlsbad, CA, USA) to generate pEFLuc, pEF-GFP and pEF- $\beta$ Gal, respectively (Figure 1).

The activity of the reporter gene components in each of the five fusion genes was assayed following transient transfection into HEK293 (human embryonic kidney) cells. Cells were grown in DMEM supplemented with

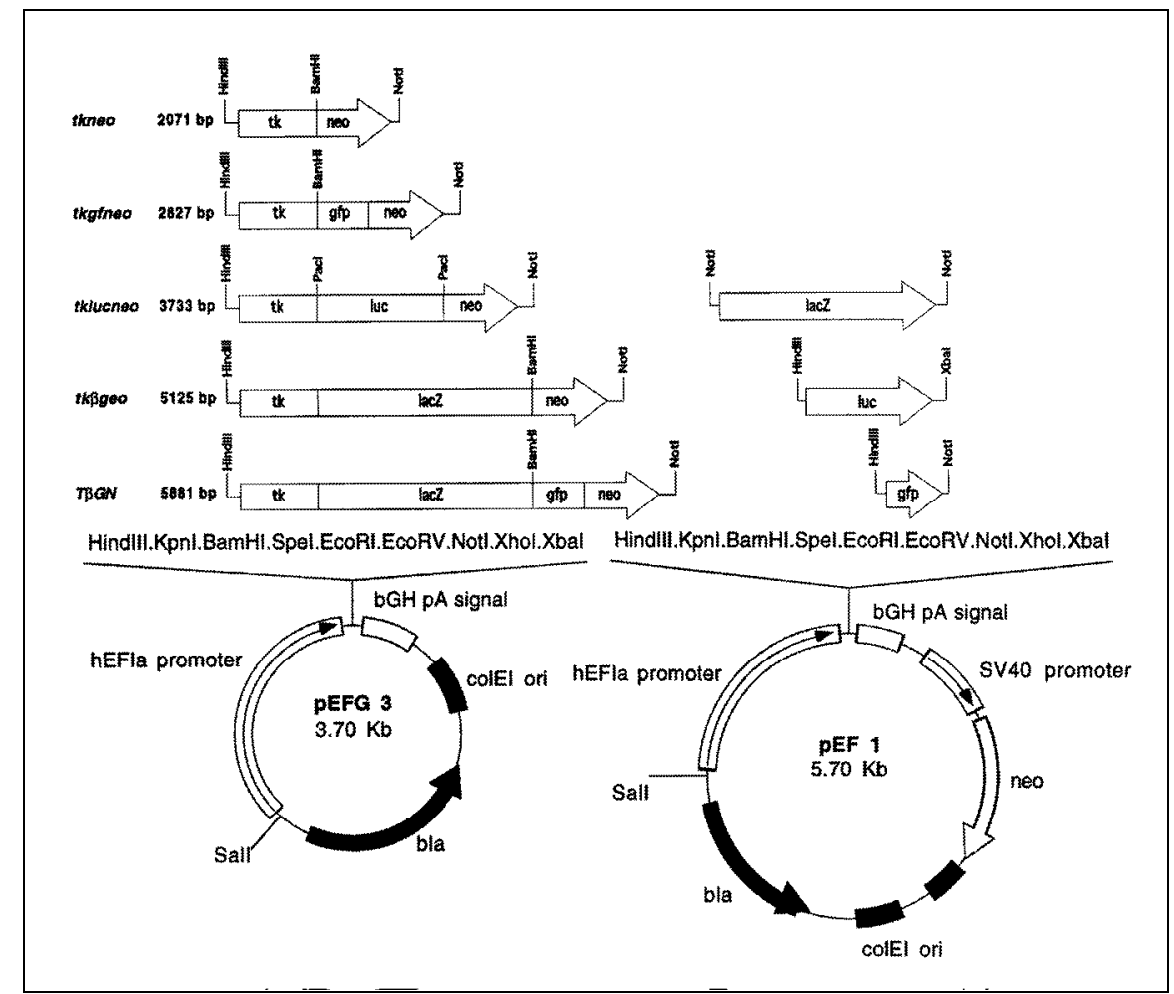

Figure 1. Gene fusions between the $l u c, g f p$, and $l a c \mathrm{Z}$ reporter genes and $t \boldsymbol{k}$ and $n e o$ selectable markers. The relative position of each reading frame is indicated for each of the five gene fusions as well as for the three parental non-fused reporter genes. The cDNAs are positioned above their respective pEFG3 and pEF1 expression vectors. Both vectors use the human elongation factor 1a promoter (9) and bovine growth hormone polyadenylation signal to control cDNA expression (10), with the pEF1 vector containing a separately expressed neo marker to provide selection for stable clones following transfection. 
Table 1. Analysis of Selectable Reporter Gene Fusions in HEK293 Cells

\begin{tabular}{|c|c|c|c|c|c|}
\hline Construct & $\begin{array}{c}\text { G418R } \\
\text { Colonies }^{\mathrm{a}}\end{array}$ & $\begin{array}{l}\text { G418R+ } \\
\text { GancyclovirR } \\
\text { Colonies }^{\mathrm{a}}\end{array}$ & $\begin{array}{l}\text { Relative } \\
\beta \text {-gal } \\
\text { Activityb,c }\end{array}$ & $\begin{array}{l}\text { Relative } \\
\text { Luciferase } \\
\text { Activityb,c }\end{array}$ & $\begin{array}{c}\text { Relative } \\
\text { GFPb,c }\end{array}$ \\
\hline pEF-GFP & 220 & 150 & 1.2 & $-d$ & 720 \\
\hline pEF- $\beta$ Gal & 164 & 147 & 180 & - & 0 \\
\hline pEF-tkneo & 286 & 0 & 0.7 & - & 0 \\
\hline pEF-tk $\beta g e o$ & 174 & 0 & 200 & - & 0 \\
\hline pEF-tkgfneo & 187 & 0 & 0.6 & - & 39 \\
\hline pEF-T $\beta G N$ & 185 & 0 & 103 & - & 16 \\
\hline pEF-Luc & 118 & 64 & - & 920 & - \\
\hline pEF-tkneo & 98 & 0 & - & 0 & - \\
\hline pEF-tklucneo & 63 & 1 & - & 52 & - \\
\hline \multicolumn{6}{|c|}{ alndependent colonies per P100 culture dish. } \\
\hline \multicolumn{6}{|c|}{$\begin{array}{l}\text { bCells were washed once in PBS, harvested, and lysed using a proprietary deter- } \\
\text { gent formulation according to manufacturers protocols (Reporter Lysis Buffer, } \\
\text { Promega, Madison WI, USA). The luciferase and } \beta \text {-gal activities in the lysates } \\
\text { were determined by assaying duplicate dilutions using commercially available } \\
\text { luminescent (Luciferase Assay System, Promega) and chemiluminescent } \\
\text { (Galacto-Light Plus, Tropix, Bedford, MA, USA) substrates. Light yield from the } \\
\text { reactions was detected using a tube format luminometer with autoinjector } \\
\text { (Lumat LB9507, EG\&G Wallac, Gaithersburg, MD, USA). The GFP in the lysates } \\
\text { was determined by assaying duplicate dilutions directly in a fluorescent plate } \\
\text { reader using an FITC filter set (Fluorescence Concentration Analyzer, IDEXX } \\
\text { Laboratories, Westbrook, ME, USA). }\end{array}$} \\
\hline \multicolumn{6}{|c|}{$\begin{array}{l}\text { "Corrected for differences in transfection efficiency by including } 5 \mathrm{ng} \text { of either } \\
\text { pGL3-Control (top series) or PCMV } \beta \text { (bottom series) (Clontech Laboratories) in } \\
\text { each reaction. }\end{array}$} \\
\hline
\end{tabular}

$10 \%$ FCS under standard culture conditions and were transfected with $1 \mu \mathrm{g}$ of plasmid DNA in a single well of a 6well culture dish using cationic liposomes according to the manufacturer's protocols (LipofectAMINE Plus ${ }^{\mathrm{TM}}$; Life Technologies, Gaithersburg, MD, USA). The results indicate that all four gene fusions that contain a reporter gene component retain their respective activities, although to a different degree in each case (Table 1). Specifically, the fusions that contain a $\beta$-galactosidase $(\beta$-gal) reporter gene retain their full activity in comparison to the $\mathrm{pEF}-\beta \mathrm{Gal}$ non-fusion control, and the fusions that contain a $l u c$ or $g f p$ reporter gene retain only approximately $5 \%$ of their activity in comparison to the respective pEF-
Luc and pEF-GFP non-fusion controls.

The activity of the selectable marker components in each of the five fusion genes was assayed using stable transfection experiments. Each linearized expression construct was transfected into HEK 293 cells as described above, and two days later the cells were divided evenly into duplicate $100 \mathrm{~mm}$ culture dishes. One dish was selected in $400 \mu \mathrm{g} / \mathrm{mL} \mathrm{G} 418$ to assay for function of the neo marker in the fusion gene, while the other dish was selected in 400 $\mu \mathrm{g} / \mathrm{mL} \mathrm{G} 418$ and $2 \mu \mathrm{M}$ gancyclovir to assay for the function of the $t k$ marker. Those transfectants selected in G418 yielded equivalent numbers of resistant colonies for each construct, including the pEF-Luc, pEF-GFP and pEF- $\beta$ Gal controls, indicating that the neo component of each of the fusion proteins retained its function (Table 1). With the exception of a single "breakthrough", the transfectants selected in G418 and gancyclovir yielded no colonies for any of the fusion genes. Because there was no effect on the number of colonies obtained in the pEF-Luc, pEF-GFP and pEF- $\beta$ Gal control transfections that do not express $t k$, this indicates that the $t k$ component of each of the fusion proteins also retained its function (Table 1).

The stable clones were assayed for $\beta$-gal activity by histochemical staining, which showed that the reporter gene activity of each fusion construct was similarly retained in all of the clones examined (Figure 2). However, only about $10 \%$ of the clones examined expressed detectable green fluorescent protein (GFP). This finding is consistent with our previous data from the transient assays for GFP, which suggests that although every clone may express the fusion gene, the reduced GFP signal will only be detectable in those that express it at high levels. Interestingly, the subcellular localization of the fusion proteins differs somewhat, with the tkgfneo fusion yielding a diffuse cytoplasmic signal similar to the non-fusion GFP control, and the T $\beta$ GN fusion yielding an intense punctate signal suggestive of incorporation into inclusion bodies (Figure 2 and References 3 and 13). Although expression levels are similar between the clones, GFP from the T $\beta$ GN fusion is easier to detect because of a significant enhancement of signal intensity.

The selectable reporter fusion genes we have developed are well suited to serve as qualitative and quantitative probes of promoter or enhancer strength. They also provide a simple mechanism to eliminate false positive clones in gene, promoter, and enhancer trapping strategies (2) by virtue of their ability to be both positively and negatively selected. In a related application, we are currently using a "floxed" version of the tklucneo fusion gene as a selectable marker in conjunction with the tetracycline-regulated transactivator expression system (4-6), where it has proven useful in the identification of stable transfectants that have a highlevel of "on" and low-level "off" 


\section{Benchmarks}
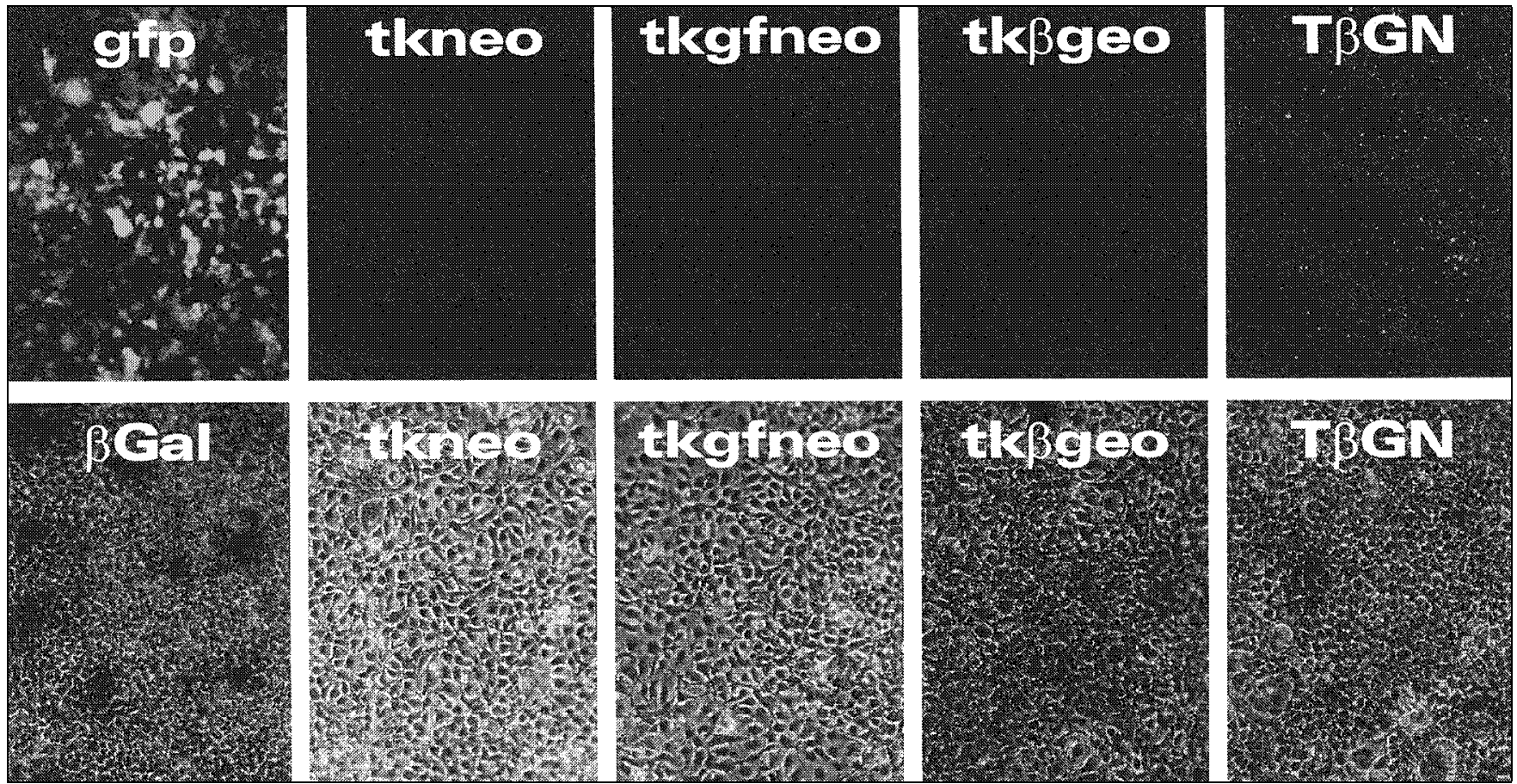

Figure 2. Detection of GFP and $\beta$-galactosidase activity in stable HEK293 clones expressing the reporter gene fusions. Cells were fixed in paraformaldehyde/glutaraldehyde using standard methods (8). GFP was detected directly using fluorescence microscopy (top row), whereas $\beta$-galactosidase activity was detected using X-gal histochemical staining (bottom row) (8). The respective fusion proteins are indicated for each panel.

expression following modulation of promoter activity by doxycycline (manuscript in preparation).

\section{REFERENCES}

1.Blochlinger, K. and H. Diggelmann. 1984. Hygromycin B phosphotransferase as a selectable marker for DNA transfer experiments with higher eucaryotic cells. Mol. Cell Biol. 4:2929-2931.

2.Friedrich, G. and P. Soriano. 1991. Promoter traps in embryonic stem cells: a genetic screen to identify and mutate developmental genes in mice. Genes Dev. 5:1513-1523.

3.Friedrich, V. L., Jr., G. R. Holstein, X. Li, A. Gow, K. A. Kelley and R. A. Lazzarini. 1993. Intracellular distribution of transgenic bacterial $\beta$-galactosidase in central nervous system neurons and neuroglia. J. Neurosci. Res. 36:88-98.

4.Gossen, M. and H. Bujard. 1992. Tight control of gene expression in mammalian cells by tetracycline-responsive promoters. Proc. Natl. Acad. Sci. USA 89:5547-5551

5.Gossen, M., S. Freundlieb, G. Bender, G. Muller, W. Hillen and H. Bujard. 1995. Transcriptional activation by tetracyclines in mammalian cells. Science 268:1766-1769.

6.Gu, H., J.D. Marth, P.C. Orban, H. Mossmann and K. Rajewsky. 1994. Deletion of a DNA polymerase $\beta$ gene segment in T cells using cell type-specific gene targeting. Science 265:103-106.

7.Lupton, S.D., L.L. Brunton, V.A. Kalberg and R.W. Overell. 1991. Dominant positive and negative selection using a hygromycin phosphotransferase-thymidine kinase fusion gene. Mol. Cell Biol. 11:3374-3378.

8.MacGregor, G.R., A.E. Mogg, J.F. Burke and C.T. Caskey. 1987. Histochemical staining of clonal mammalian cell lines expressing E. coli $\beta$-galactosidase indicates heterogeneous expression of the bacterial gene. Somat. Cell Mol. Genet. 13:253-265.

9.Mizushima, S. and S. Nagata. 1990. pEFBOS, a powerful mammalian expression vector. Nucleic Acids Res. 18:5322.

10.Pfarr, D. S., L.A. Rieser, R.P. Woychik, F.M. Rottman, M. Rosenberg and M.E. Reff. 1986. Differential effects of polyadenylation regions on gene expression in mammalian cells. DNA 5:115-122.

11.Smith, K.O., K.S. Galloway, W.L. Kennell, K.K. Ogilvie and B.K. Radatus. 1982. A new nucleoside analog, 9-[[2-hydroxy-1-(hydroxymethyl)ethoxyl]methyl]guanine, highly active in vitro against herpes simplex virus types 1 and 2. Antimicrob. Agents Chemother. 22:5561.

12.Southern, P.J. and P. Berg. 1982. Transformation of mammalian cells to antibiotic resistance with a bacterial gene under control of the SV40 early region promoter. J. Mol. Appl. Genet. 1:327-341.

13.Tu, P.H., K.A. Robinson, F. de Snoo, J. Eyer, A. Peterson, V.M. Lee and J.Q. Trojanowski. 1997. Selective degeneration of Purkinje cells with Lewy body-like inclusions in aged NFHLACZ transgenic mice. J. Neurosci. 17:10641074.

14.Tybulewicz, V.L., C.E. Crawford, P.K. Jackson, R.T. Bronson and R. C. Mulligan. 1991 Neonatal lethality and lymphopenia in mice with a homozygous disruption of the c-abl pro- to-oncogene. Cell 65:1153-1163.

15.Wei, C.M., M. Gibson, P.G. Spear and E.M. Scolnick. 1981. Construction and isolation of a transmissible retrovirus containing the src gene of Harvey murine sarcoma virus and the thymidine kinase gene of herpes simplex virus type 1. J. Virol. 39:935-944.

We thank Chris Pászty and Phil Soriano for generously providing the pPNT and p $\beta$ geo constructs, respectively. This research was supported by grants from the ALS Society of Canada (C.A.S.) and Medical Research Council of Canada (T.M.U.). C.A.S. is a Cancer Research Society/Medical Research Council of Canada Scholar. Address correspondence to Dr. Craig A. Strathdee, Robarts Research Institute, 100 Perth Drive, London, ON N6A 5K8, Canada.Internet: cas@rri.on.ca

Received: 29 July 1999; accepted 9 November 1999.

\section{Craig A. Strathdee, Marilyn R. McLeod and T. Michael Underhill \\ The John P. Robarts Research Institute and University of Western Ontario London, ON, Canada}

